\title{
Editorial
}

\section{Evaluating Impact of High-Cost Cancer Drugs at Regional Level: The Case of Veneto (Italy)}

\author{
Dario Gregori ${ }^{*} \S$ and Daniele Chiffi ${ }^{\S}$
}

Unit of Biostatistics, Epidemiology and Public Health, Department of Cardiac, Thoracic and Vascular Sciences, University of Padova, Padova, Italy

In Italy, the National Health System (NHS) costs are controlled by the regional governments (which are financially accountable for health care expenditure, including hospital drug budgets), but agreements regarding price and discounts are decided in AIFA (Italian Medicine Agency). For this reason, some regional governments ask the pharmaceutical companies to produce a "Health Technology Assessment" before deciding to introduce a drug in the regional hospital list of accepted drugs. Thus, in terms of public policy maker and its decision process, the choice of well-specified points of view is an essential ingredient in the critical assessment of economic evaluation, which becomes more effective when information is presented in the general terms of a cost of illness analysis (COI), or, in a disaggregated way by means of a list of the costs and the

\footnotetext{
*Address correspondence to this author at the Unit of Biostatistics, Epidemiology and Public Health, Department of Cardiac, Thoracic and Vascular Sciences, Via Loredan 18, 35121 Padova, Italy; Tel: +39 049 8275384; Fax:+3902 700445089 ; E-mail: dario.gregori@unipd.it

${ }^{\S}$ Guest Editor.
}

outcomes or consequences of the intervention, namely as a cost consequence analysis (CCA).

Furthermore, while it has been observed that economic evaluations are usually performed in different countries at national level, in local health care decision making there is lack of health economic data and evaluations, disconnecting economic evaluations from the types of decision that local institutions must normally face.

The University of Padova financed a composite and interdisciplinary group of researchers to develop a proof-ofconcept like program aimed at serving the Veneto region as a template for the evaluation of the impact of (high-cost) drugs. The program, financed as "Progetti di Ateneo" 2009, (Code CPDA093183/09, "Modello per la valutazione dell'impatto economico, sociale e di salute derivante dall'utilizzo dei nuovi farmaci oncologici nella regione Veneto") has come now to its end and this report represents the outcome of a two-year intense research work.

Gratefully, the leading investigators acknowledge the contribution of the entire EIHCD-VeRo Research Project Agreement for their help and cooperation at the various stages of the project development. 